\title{
Non-invasive diagnosis of subpulmonary outflow tract obstruction
}

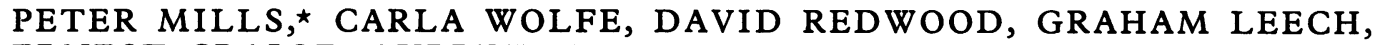 \\ ERNEST CRAIGE, AUBREY LEATHAM \\ From the Cardiac Department, St. George's Hospital, London; and Division of Cardiology, University of \\ North Carolina, Chapel Hill, USA
}

SUMMARY We have studied the echocardiographic and phonocardiographic findings in 18 patients with obstruction to ventricular outflow at subpulmonary valve level. The aetiology was congenital in 13 patients, a result of hypertrophic cardiomyopathy in three, and infiltration of the right ventricular outflow tract by glycogen or lymphoma in the remaining two.

Abnormal systolic motion of the pulmonary valve, fluttering, and early or midsystolic closure were seen in 16 of the 17 patients in whom the cusps were visualised. Normal pulmonary valve motion was found in one patient with coexisting pulmonary valve stenosis. In congenital infundibular stenosis the delay of the pulmonary component of the second heart sound (P2) was related to the severity of the obstruction. A pulmonary ejection sound, defined as a high-frequency sound occurring at the moment of full pulmonary valve opening, was absent except in the patient with coexisting pulmonary valve stenosis. In hypertrophic cardiomyopathy with obstruction to the right ventricular outflow, the ejection systolic murmur was softer with inspiration, a finding that contrasts with the respiratory variation seen with fixed obstruction.

Recognition of these abnormalities should allow an accurate non-invasive diagnosis to be made and permit assessment of severity when P2 can be recorded.

The clinical diagnosis of right ventricular outflow tract obstruction depends upon the recognition of an ejection systolic murmur together with delay of the pulmonary component of the second heart sound (P2). Congenital infundibular stenosis is, however, often associated with other anomalies, particularly ventricular septal defect. The murmur from the ventricular septal defect tends to obscure that from the obstruction to right ventricular outflow, and recognition of the delayed P2 becomes particularly important. In patients with hypertrophic cardiomyopathy, obstruction to right ventricular outflow may occur. This is easily overlooked if clinical assessment has not pointed to the need for careful right ventricular pressure tracings and right ventricular angiography.

Because of the difficulties associated with making the diagnosis of right ventricular outflow tract obstruction at subvalvar level, the present study

\footnotetext{
* Supported by a grant from the Jensen Medical Research Foundation. Present address: The London Hospital, Whitechapel, London E1.

Received for publication 2 July 1979
}

was undertaken to evaluate the echocardiographic and phonocardiographic findings in 18 patients with this condition. The aetiology of the obstruction was congenital in 13, and the result of hypertrophic cardiomyopathy, glycogen storage disease, or right ventricular tumour in the other five.

\section{Subjects}

\section{PATIENTS}

Eighteen patients with subvalvar obstruction to right ventricular outflow were studied. Their ages ranged from 3 weeks to 71 years. Twelve of the 18 patients were encountered during routine echocardiographic and phonocardiographic screening before cardiac catheterisation. Six other patients with previously documented right ventricular outflow tract obstruction were identified from the diagnostic indices at St. George's Hospital and North Carolina Memorial Hospital, and were studied retrospectively. The results of cardiac catheterisation and, when available, surgical and pathological findings, are summarised in the Table. 


\section{CONGENITAL INFUNDIBULAR STENOSIS}

Cases 1 to 10 had congenital infundibular pulmonary stenosis. In three (cases 1,2 , and 8 ) this was the only cardiac anomaly, but in the other seven patients (cases 3 to 7,9 , and 10) there was an associated ventricular septal defect. One patient (case 10) had coexisting pulmonary valve stenosis. Of these 10 patients, three (cases 1 to 3) were studied echocardiographically both before and after successful surgical correction. One patient (case 9) had not been studied before operation. After surgical resection of infundibular pulmonary stenosis and closure of a ventricular septal defect, a residual infundibular gradient of $25 \mathrm{mmHg}$ had been found at cardiac catheterisation.

\section{TRANSPOSITION WITH SUBPULMONARY} OBSTRUCTION

Two patients (cases 11 and 12) had d-transposition of the great vessels in addition to subpulmonary valve obstruction to left ventricular outflow and one (case 13) had l-transposition.

\section{HYPERTROPHIC CARDIOMYOPATHY}

Three patients (cases 14 to 16 ) had the typical clinical, echocardiographic (septal left ventricular posterior wall ratio greater than $1 \cdot 5: 1$ ), haemodynamic, and angiographic findings of hypertrophic cardiomyopathy. Electrocardiographic abnormalities were similar in all three; there were deep $Q$ waves but positive $T$ wave deflections in leads II, III, and aVF, with similar changes in leads V5 and V7.

All three had undergone cardiac catheterisation (Table). In case 14 there were resting gradients of $60 \mathrm{mmHg}$ across the right ventricular outflow tract and $20 \mathrm{mmHg}$ across the left ventricular outflow tract, these increasing to 100 and $60 \mathrm{mmHg}$, respectively, on provocation with isoprenaline. At operation, the right ventricular outflow tract was found to be much narrowed by encroachment of the greatly thickened interventricular septum, and part of this was successfully resected leaving no gradient. In case 15 simultaneous right ventricular and pulmonary artery pressures disclosed a gradient of $15 \mathrm{mmHg}$ across the right ventricular outflow tract. There was no gradient across the left ventricular outflow tract at rest or on provocation with isoprenaline or amyl nitrate. Simultaneous left and right ventricular angiograms confirmed the presence of a thickened interventricular septum and the typical angiographic features of hypertrophic cardiomyopathy. In case 16 the haemodynamic findings were similar to those in case 15 (Table).

MYOCARDIAL INFILTRATION

The remaining two patients presented with rare causes of right ventricular outflow tract obstruction. Case 17 was an infant of 3 weeks who presented with respiratory distress and cardiac failure. Chest $x$-ray film showed cardiomegaly and the electrocardiogram showed a short PR interval and biventricular hypertrophy. Echocardiography disclosed prominent asymmetrical septal hypertrophy and systolic anterior motion of the mitral valve. At cardiac catheterisation there was a resting gradient of $25 \mathrm{mmHg}$ across the right ventricular outflow tract, and a gradient of $40 \mathrm{mmHg}$ across the left ventricular outflow tract. Right ventricular angiography showed distinct encroachment of the septum on the right ventricular outflow tract. Surgery was not attempted and the infant's condition deteriorated until he died one week later. At necropsy there were contact lesions on the anterior mitral valve leaflet and the left ventricular aspect of the interventricular septum. The cause of the greatly hypertrophied left and right ventricular free walls and interventricular septum was found to be the result of infiltration by glycogen-Pompe's disease.

Case 18 was a 71-year-old man who presented with a four-week history of increasing weakness and breathlessness. On examination there were large systolic waves in the jugular venous pulse and an ejection systolic murmur was heard at the pulmonary area. The electrocardiogram showed left axis deviation and no evidence of right ventricular hypertrophy; the chest $x$-ray film showed slight cardiomegaly and a prominent left heart border compatible with enlargement of the right ventricular outflow tract. At cardiac catheterisation there was a peak systolic gradient of $55 \mathrm{mmHg}$ between the right ventricle and the pulmonary artery. Right ventricular angiography showed multiple lobular filling defects within the right ventricle. Subsequent necropsy showed that the right ventricular cavity and outflow tract had been invaded by a lymphoma which was responsible for the obstruction to outflow.

\section{Methods}

Echocardiograms and phonocardiograms were recorded using either a Smith Kline ultrasonoscope interfaced with a Cambridge multichannel physiological recorder, or an Irex multichannel physiological recorder. High-frequency phonocardiograms from the pulmonary and mitral areas together with the carotid pulse and electrocardiogram were recorded at a paper speed of $100 \mathrm{~mm} / \mathrm{s}$. After the recording of the routine echocardiogram, the pulmonary valve echocardiogram was recorded at a paper speed of 100 or $200 \mathrm{~mm} / \mathrm{s}$, with appropriate magnification of the echo signal. 
Combined tracings of the pulmonary valve echocardiogram and a high-frequency phonocardiogram from the pulmonary area were also recorded. The presence or absence of a pulmonary ejection sound, and correlation of pulmonary valve closure with the pulmonary component of the second heart sound can be accurately assessed from such tracings.

\section{Results}

(1) CONGENITAL INFUNDIBULAR PULMONARY STENOSIS (CASES 1 TO 9)

(A) Echocardiographic findings

In each patient the echocardiogram showed fine systolic fluttering of the pulmonary valve. This was superimposed on a pattern of either early or midsystolic cusp closure or coarse chaotic cusp motion throughout systole (Fig. 1). In three patients the posterior pulmonary cusp clearly moved to a 'closed' position in mid-systole (Fig. 2). One patient had low infundibular stenosis caused by abnormal muscle bands ('double chambered right ventricle'). ${ }^{1}$ The abnormality of pulmonary valve motion in this patient could not be distinguished from that seen in the patients with true infundibular stenosis. The presence or absence of an associated ventricular septal defect did not affect the echocardiographic abnormalities.

In three patients who underwent successful surgical resection of the obstruction, postoperative echocardiographic studies showed normal systolic pulmonary valve motion and increased amplitude of the ' $a$ ' dip (Fig. 3). In contrast, systolic fluttering and early closure of the pulmonary valve were

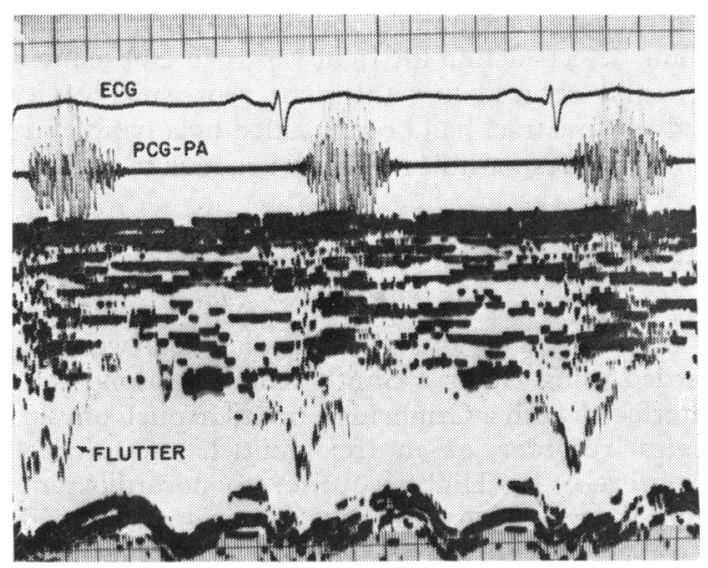

Fig. 1 Fine fluttering of the pulmonary valve in case 2 with congenital infundibular stenosis. Slight alterations of the transducer angle show different patterns on each cardiac cycle. PCG-PA, phonocardiogram in pulmonary area. demonstrated in the patient who, after resection of infundibular pulmonary stenosis, was shown at cardiac catheterisation to have a residual gradient of $25 \mathrm{mmHg}$ (Fig. 4).

\section{(B) Echophonocardiography}

A pulmonary ejection sound, defined as a highfrequency sound coinciding with full pulmonary cusp opening, was not recorded in any of these patients. In three patients, including two in whom P2 could not be recorded, closure of the anterior pulmonary cusp was recorded after the end of the murmur, showing that right ventricular systole was prolonged (Fig. 5).

\section{(C) Phonocardiographic findings}

The pulmonary component of the second heart sound (P2) was recorded in seven of these nine patients. The degree of delay of $\mathbf{P 2}$ relative to A2 during expiration was related to the severity of the obstruction (Table), being 0.09 second with a gradient of $100 \mathrm{mmHg}$ (case 2), and 0.02 second with a gradient of $15 \mathrm{mmHg}$. The presence of right bundle-branch block accounts for 0.04 second of the delay of P2 in case 9 with a postoperative gradient of $25 \mathrm{mmHg}$.

(2) CONGENITAL INFUNDIBULAR PULMONARY STENOSIS WITH VALVULAR PULMONARY

STENOSIS

In case 10 both infundibular stenosis and pulmonary valve stenosis were present. In contrast to patients with pure infundibular stenosis, systolic motion of the pulmonary valve was normal. In addition a pulmonary ejection sound, softer than that usually found with pure pulmonary valve stenosis, was recorded at the time of full pulmonary cusp opening.

\section{(3) SUBPULMONARY STENOSIS WITH TRANSPOSITION}

In three patients (cases 11 to 13) with transposition of the great vessels there was obstruction to left ventricular outflow below the pulmonary valve. In each of these patients the second heart sound was single because of posterior location of the pulmonary valve which rendered the pulmonary component inaudible.

Fluttering of the posterior semilunar (pulmonary) cusps and partial early or mid-systolic valve closure were seen in all three patients (Fig. 6).

(4) HYPERTROPHIC CARDIOMYOPATHY WITH RIGHT VENTRICULAR OUTFLOW TRACT OBSTRUCTION (CASES 14, 15, AND 16) The pulmonary valve was visualised in two of these three patients, systolic motion showing similar 


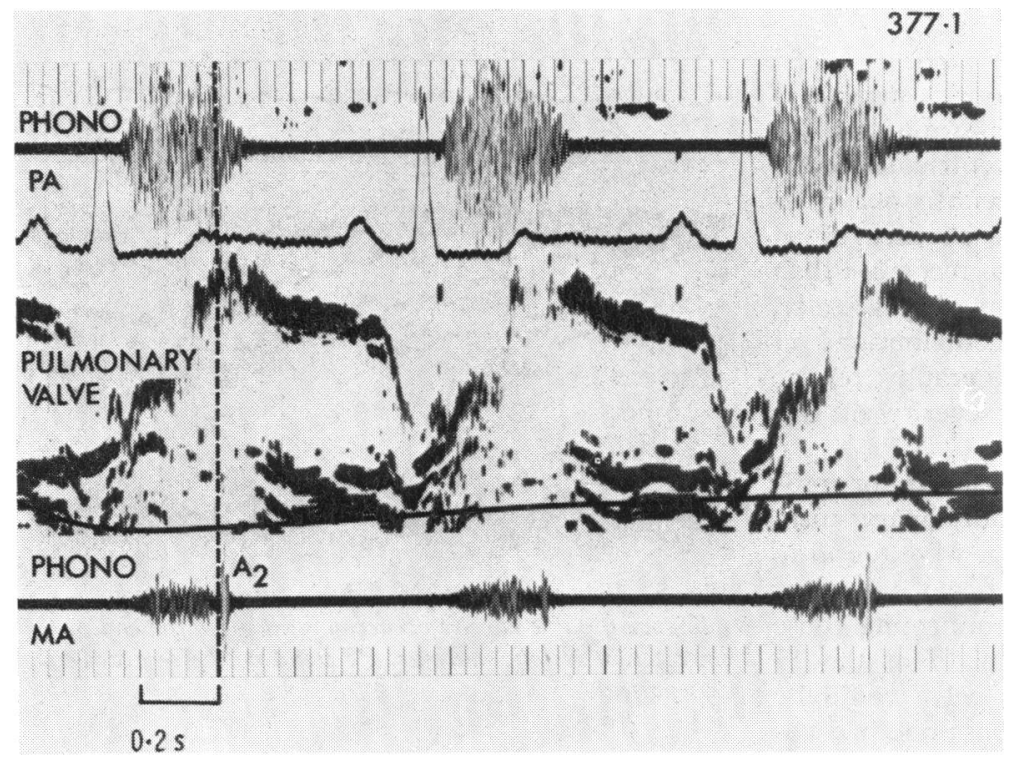

Fig. 2 Echophonocardiographic study of the pulmonary valve in case 1 . The pulmonary valve opens before the $Q R S$ on the electrocardiogram. The initial opening motion is a result of the large ' $a$ ' wave associated with right atrial hypertrophy. The pulmonary cusp flutters throughout systole and closes midway through the pulmonary ejection systolic murmur. P2 not recorded. Continued vibration can be seen on the pulmonary cusp throughout right ventricular systole, and extending past $A 2$. $M A$, mitral area.

abnormalities to those seen in patients with infundibular pulmonary stenosis. In the third patient pulmonary valve motion could not be recorded. In one patient (case 14) who underwent successful myectomy of the right ventricular outflow tract and interventricular septum, pulmonary valve motion returned to normal postoperatively.

Because of the absence of pulmonary artery

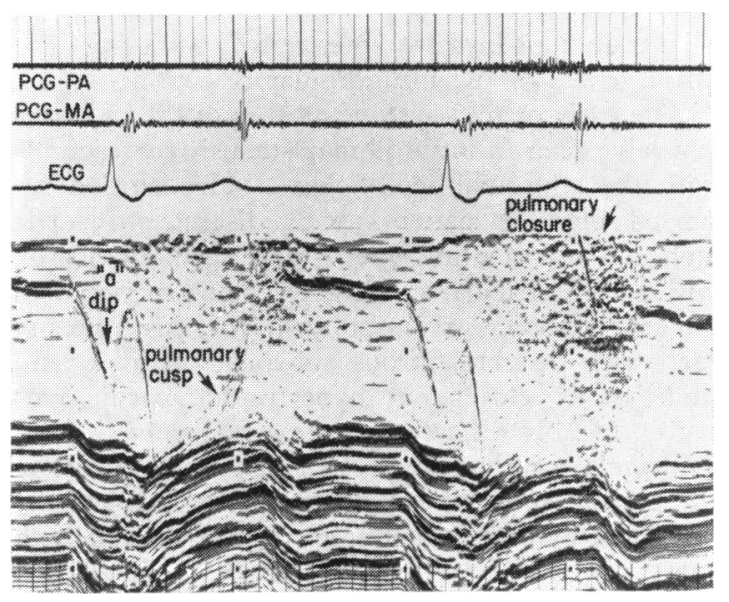

Fig. 3 Postoperative pulmonary valve echocardiogram from case 3. Pulmonary cusp systolic motion is now normal (best seen in first cardiac cycle). There is no fluttering or early closure of the cusp. The second cardiac cycle shows the closing motion of the anterior pulmonary cusp-a reliable guide to the end of right ventricular systole. This is not delayed in relation to the second heart sound. A large ' $a$ ' dip is still present. dilatation in this group the pulmonary valve was difficult to record. The phonocardiographic abnormalities were therefore particularly important. As with congenital infundibular stenosis, P2 was delayed, though the sound was not diminished in intensity. There was no pulmonary ejection sound. The ejection systolic murmur in the pulmonary area increased in expiration and decreased with inspiration, the converse pattern to that found with fixed right ventricular outflow tract obstruction (Fig. 7).

\section{(5) INFILTRATIVE DISORDERS}

In case 16, the infant with Pompe's disease, echocardiography identified all the abnormalities simulating hypertrophic cardiomyopathy which were subsequently shown at cardiac catheterisation and necropsy. Apart from showing distinct asymmetrical septal hypertrophy, systolic anterior motion of the mitral valve, and early systolic closure of the aortic valve, echocardiography showed progressive closure and fine fluttering of the pulmonary valve throughout systole (Fig. 8). P2 could not be recorded.

In the patient in whom metastatic lymphoma caused obstruction to the right ventricular outflow echophonocardiographic studies were critical in establishing the presence of prolonged right ventricular systole. These recordings showed a delayed pulmonary component of the second heart sound which clinically had been thought to be a right ventricular third heart sound. The pulmonary valve showed fluttering throughout systole and a reduced opening excursion. 


\section{Discussion}

The clinical detection of subpulmonary stenosis is often difficult because the systolic murmur may be obscured by that of an associated ventricular septal defect. Even when infundibular stenosis occurs as an isolated lesion, because of the absence of an ejection sound it is more difficult to recognise than pulmonary valve stenosis. The aim of this study, therefore, was to examine the contributions of echocardiography and phonocardiography to the diagnosis and assessment of the severity of this lesion.

The echocardiographic findings of early or midsystolic closure of the posterior pulmonary cusp, together with fine systolic fluttering, were found to be a sensitive indicator of the presence of subvalvar obstruction. These observations, confirming those of Weyman et al., ${ }^{2}$ were made in 15 of the 17 patients in whom the pulmonary valve could be recorded. There were two exceptions; one had coexisting pulmonary valve stenosis, and the thickened and stiff pulmonary cusps were unable to vibrate rapidly. In the patient with lymphoma, the tumour extended up through the valve ring preventing partial closure during systole, and hence only fluttering was seen.

Septal thickening indicating right ventricular hypertrophy was recorded in two patients but otherwise echocardiography was unhelpful in assessing the severity of the obstruction.

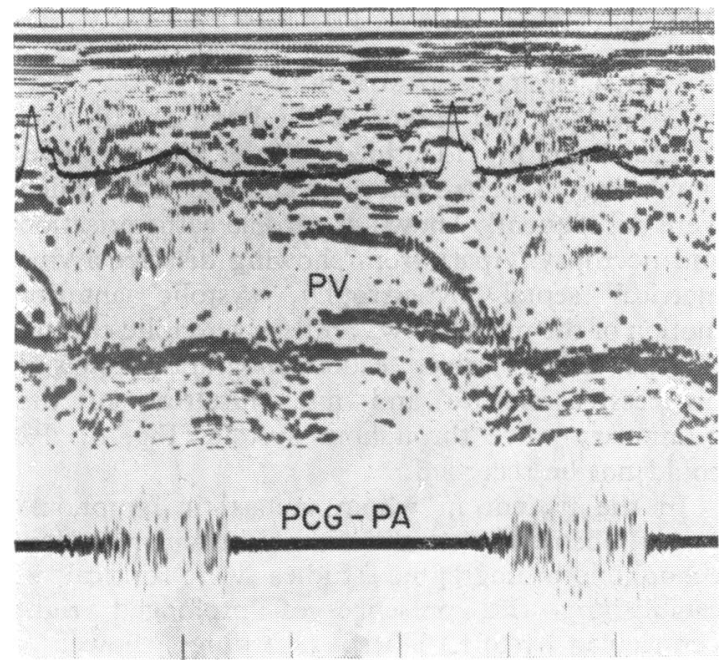

Fig. 4 Pulmonary valve echocardiogram in a patient with residual infundibular stenosis after operation. The pulmonary valve begins to close at the start of the systolic murmur, and flutters in the closed position during the remainder of systole. $P V$, pulmonary valve.

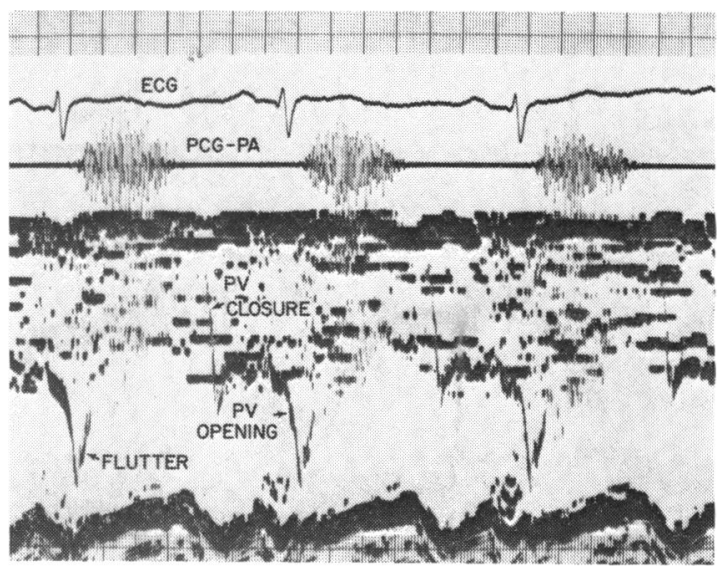

Fig. 5 Echocardiographic study in case 2 showing pulmonary valve closure occurring well after the end of the ejection systolic murmur. P2 could not be recorded in this patient.

After successful surgical resection of the stenosis in four patients, pulmonary valve systolic motion returned to normal. In contrast, in the patient shown to have a $25 \mathrm{mmHg}$ residual gradient postoperatively, the typical echocardiographic features of subvalvar obstruction were retained. The delay of P2 was 0.07 second, and allowing 0.04 second for the presence of right bundle-branch block, the 'corrected delay' of 0.03 second correctly suggested that the residual gradient was not severe. Thus echocardiography and phonocardiography provide a useful non-invasive means of assessing the effectiveness of the infundibular resection.

The early or mid-systolic closure of the pulmonary valve seen in infundibular stenosis corresponds with the abnormalities of aortic valve motion reported both in patients with discrete subaortic stenosis $^{3}$ and also in hypertrophic cardiomyopathy with left ventricular outflow tract obstruction. ${ }^{4}$ In our experience, early systolic aortic cusp closure seen with discrete fibrous subaortic stenosis, and mid-systolic closure in hypertrophic cardiomyopathy, reliably differentiate these two causes of left ventricular outflow tract obstruction. However, in the present series, we were unable to correlate the abnormal pattern of pulmonary valve motion with the cause of subvalvar obstruction. In particular, we found that congenital infundibular stenosis, double chamber right ventricle, and hypertrophic cardiomyopathy could not be distinguished.

The exception to this observation occurred in patients with transposition. Here the cause of the subpulmonary obstruction is usually a typical discrete membrane in the anatomical left ventricle, and the pattern of early systolic closure of the 
pulmonary valve was the same as that seen in membranous subaortic stenosis (Fig. 6). In one patient the presence of such a membrane just below the pulmonary valve was confirmed at operation. Similar findings have been previously noted in a single case. ${ }^{5}$

It should be emphasised that systolic fluttering of semilunar cusps is a non-specific finding reflecting turbulent flow past the valve. We have seen pronounced systolic fluttering in two patients in whom no gradient could be detected across the infundibulum. One had an atrial septal defect with a left-to-right shunt of $4: 1$ and the other a cardiac output of $81 / \mathrm{min}$. In both cases there was relative obstruction at infundibular level caused by increased flow across a normal outflow tract. In this instance the echocardiographic finding of fine fluttering may be considered as a 'false positive' in terms of predicting an anatomical subvalvar obstruction.

So far we have not encountered this echocardiographic abnormality with a ventricular septal defect, though, theoretically, this could occur if the shunt were sufficiently large. We have not found abnormalities of pulmonary valve motion in Fallot's tetralogy, nor have any been reported. ${ }^{6} 7$ Two factors contribute to this. Technically satisfactory pulmonary valve echocardiograms are usually only obtained from patients with normal or enlarged pulmonary arteries. With infundibular pulmonary stenosis the pulmonary artery at the level of the pulmonary valve is often normal or dilated, ${ }^{8}$ whereas in Fallot's tetralogy the pulmonary outflow tract is invariably hypoplastic, often preventing the pulmonary valve being satisfactorily recorded. Secondly, many patients with Fallot's tetralogy have dysplastic or stenotic pulmonary valves which may prevent fluttering of the pulmonary cusps.

There were a number of occasions on which it proved useful to record simultaneous echocardiograms and phonocardiograms. Such tracings allow careful examination of the phonocardiogram at the time of complete pulmonary valve opening, and this is especially important when deciding that the initial vibrations of a systolic murmur do not

Table

\begin{tabular}{|c|c|c|c|c|c|c|}
\hline $\begin{array}{l}\text { Case } \\
\text { no. }\end{array}$ & $\begin{array}{l}\text { Age } \\
(y)\end{array}$ & Diagnosis & $\begin{array}{l}\text { Confirmation of } \\
\text { diagnosis }\end{array}$ & $\begin{array}{l}\text { Pressure gradient across } \\
\text { outflow tract }(\mathrm{mmHg})\end{array}$ & $\begin{array}{l}\text { A2-P2 in } \\
\text { expiration }\end{array}$ & $\begin{array}{l}\text { Pulmonary valve echo } \\
\text { findings }\end{array}$ \\
\hline 1 & 20 & $\begin{array}{l}\text { Double chamber right } \\
\text { ventricle }\end{array}$ & RV angio, surgery & 125 & $\begin{array}{l}\text { P2 not } \\
\text { recorded }\end{array}$ & $\begin{array}{l}\text { Mid-systolic closure and } \\
\text { fluttering }\end{array}$ \\
\hline 2 & 10 & Isolated IPS & RV angio, surgery & 100 & 0.09 & $\begin{array}{l}\text { Early systolic closure and } \\
\text { fluttering }\end{array}$ \\
\hline 3 & 25 & IPS and VSD & $\mathrm{RV}$ angio, surgery & 95 & 0.09 & $\begin{array}{l}\text { Mid-systolic closure and } \\
\text { fluttering }\end{array}$ \\
\hline 5 & 10 & IPS and VSD & RV angio & 45 & $\begin{array}{l}\text { P2 not } \\
\text { recorded }\end{array}$ & $\begin{array}{l}\text { Early systolic closure and } \\
\text { fluttering }\end{array}$ \\
\hline 6 & 23 & IPS and VSD & RV angio & 50 & 0.07 & $\begin{array}{l}\text { Mid-systolic closure and } \\
\text { fluttering }\end{array}$ \\
\hline 7 & 28 & IPS and VSD & RV angio & 25 & $\begin{array}{l}\text { P2 not } \\
\text { recorded }\end{array}$ & $\begin{array}{l}\text { Partial closure and } \\
\text { fluttering }\end{array}$ \\
\hline 8 & 15 & Isolated IPS & $\begin{array}{l}\text { Pressure gradient } \\
\text { alone }\end{array}$ & 15 & 0.02 & $\begin{array}{l}\text { Partial closure and } \\
\text { fluttering }\end{array}$ \\
\hline 10 & 5 & $\begin{array}{l}\text { IPS and VSD; pulmonary } \\
\text { valve stenosis }\end{array}$ & RV angio & $55^{\star}$ & 0.07 & $\begin{array}{l}\text { Normal systolic motion, no } \\
\text { fluttering }\end{array}$ \\
\hline 11 & $3 \mathrm{wk}$ & $\begin{array}{l}\text { ASD and IPS; d- } \\
\text { transposition }\end{array}$ & $\mathrm{LV}$ angio & $\begin{array}{l}\text { Not measured; LV } \\
\text { systolic pressure } 75\end{array}$ & $\begin{array}{l}\mathrm{P} 2 \text { not } \\
\text { recorded }\end{array}$ & $\begin{array}{l}\text { Early systolic closure and } \\
\text { fluttering }\end{array}$ \\
\hline 12 & 4.5 & $\begin{array}{l}\text { ASD, VSD, and IPS; d- } \\
\text { transposition }\end{array}$ & $\begin{array}{l}\text { LV angio, surgery, } \\
\text { necropsy }\end{array}$ & 80 & $\begin{array}{l}\text { P2 not } \\
\text { recorded }\end{array}$ & $\begin{array}{l}\text { Early systolic closure and } \\
\text { fluttering }\end{array}$ \\
\hline 13 & 27 & $\begin{array}{l}\text { L-transposition; IPS and } \\
\text { VSD }\end{array}$ & LV angio & 100 & $\begin{array}{l}\text { P2 not } \\
\text { recorded }\end{array}$ & $\begin{array}{l}\text { Early systolic closure and } \\
\text { fluttering }\end{array}$ \\
\hline 14 & 36 & $\begin{array}{l}\text { HCM R and L; ventricular } \\
\text { outflow tract obstruction }\end{array}$ & RV angio, surgery & 60 & 0.07 & $\begin{array}{l}\text { Mid-systolic closure and } \\
\text { fluttering }\end{array}$ \\
\hline 15 & 43 & $\begin{array}{l}\text { HCM, no resting LV outflow } \\
\text { tract obstruction }\end{array}$ & $\mathrm{RV}$ angio & 15 & 0.05 & $\begin{array}{l}\text { Pulmonary valve not } \\
\text { visualised }\end{array}$ \\
\hline 16 & 16 & $\begin{array}{l}\text { HCM, no resting LV outflow } \\
\text { obstruction }\end{array}$ & $\mathrm{RV}$ angio & 10 & 0.06 & $\begin{array}{l}\text { Early systolic closure and } \\
\text { fluttering }\end{array}$ \\
\hline 17 & 3 wk & $\begin{array}{l}\text { Pompe's disease; } R \text { and } L \\
\text { ventricular outflow tract } \\
\text { obstruction }\end{array}$ & $\begin{array}{l}\text { RV angio, } \\
\text { necropsy }\end{array}$ & 25 & $\begin{array}{l}\text { P2 not } \\
\text { recorded }\end{array}$ & $\begin{array}{l}\text { Progressive systolic closure } \\
\text { and fluttering }\end{array}$ \\
\hline
\end{tabular}

* Gtadient across pulmonary valve $40 \mathrm{mmHg}$. Gradient across infundibulum $15 \mathrm{mmHg}$.

IPS, infundibular pulmonary stenosis; VSD, ventricular septal defect; HCM, hypertrophic cardiomyopathy; ASD, atrial septal defect;

RV, right ventricle; A2-P2, time interval between the aortic and pulmonary components of the second heart sound measured in seconds;

RBBB, right bundle-branch block; RV angio, right ventricular angiogram; LV angio, left ventricular angiogram. 
include a soft ejection sound. Using this technique, we found that irrespective of the size of the pulmonary artery, there was no ejection sound in patients with subvalvar obstruction. This confirms the value of this sign in differentiating valvar from subvalvar stenosis, and provides further confirmation of the hypothesis that ejection sounds only originate from abnormal semilunar valve cusps. It should be noted that with severely dysplastic stenotic pulmonary valves the ejection sound may be undectectable. ${ }^{9}$

Echophonocardiography is also of value for studying the end of systole. In two of the three patients with congenital infundibular stenosis in whom P2 could not be recorded, delayed closure of the anterior leaflet of the pulmonary valve provided the only evidence of prolongation of right ventricular systole. Similarly, in case 18 the presence of tricuspid regurgitation in a 71-year-old man suggested that the sound in early diastole was a right ventricular third sound. However, the combined echophonocardiographic study revealed that this was in fact a delayed P2 which, together with the systolic fluttering of the pulmonary cusps, correctly suggested right ventricular outflow tract obstruction. Similar findings have been reported in a patient with a right ventricular myxoma. ${ }^{10}$ Finally, the pattern of pulmonary valve motion in primary pulmonary hypertension ${ }^{11} 12$ is similar to that seen with infundibular stenosis. The two diagnoses may

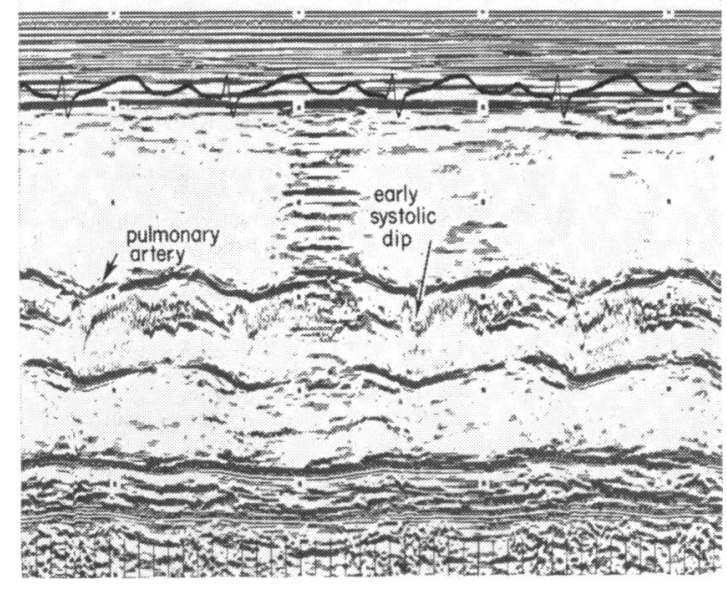

Fig. 6 Pulmonary valve echocardiogram in case 11 with d-transposition and discrete membranous obstruction to left ventricular outflow. The pattern of early systolic closure and subsequent systolic flutter in the semi-closed position is the same as that seen on the aortic cusps with membranous subaortic stenosis.

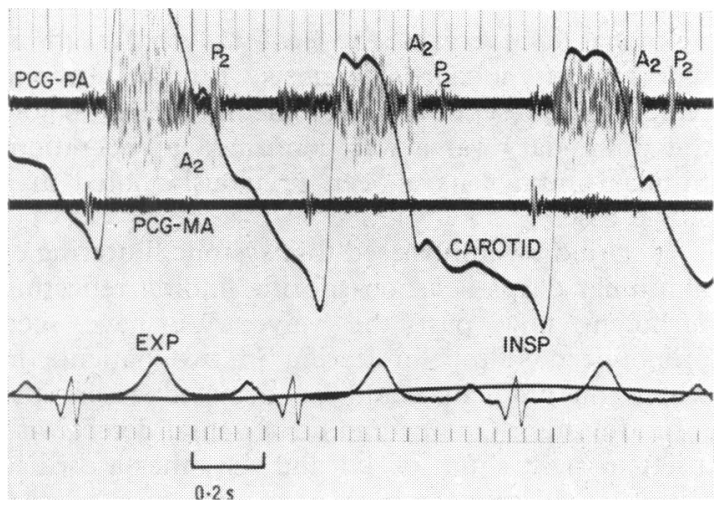

Fig. 7 Phonocardiogram from case 14. The ejection systolic murmur in the pulmonary area is maximal in expiration and attenuated during inspiration. $P 2$ is loudest in expiration, and is delayed 0.07 seconds after A2. In inspiration $P 2$ is softer and delayed to $0 \cdot 10$ seconds after $A 2$.

be distinguished by the phonocardiographic findings in pulmonary hypertension of a loud P2 which is not delayed and the absence of a systolic murmur.

The delay in P2, caused by prolongation of right ventricular systole, is an important diagnostic feature of infundibular stenosis. In addition, we have confirmed the previous observation that phonocardiographic documentation of the delay in P2 provides a useful means of assessing the severity of the obstruction. ${ }^{13}$ In the patients with hypertrophic cardiomyopathy, however, the delay in P2 was greater than would be expected from the gradient subsequently documented at cardiac catheterisation. Similar prolongation of right ventricular systole was also shown by the patient (case 18) with florid right ventricular failure resulting from acquired infundibular obstruction. This finding is analogous to reversed splitting of the second sound in aortic stenosis with impaired left ventricular function.

Previous studies have emphasised that the clinical recognition of right ventricular outflow obstruction in hypertrophic cardiomyopathy may be difficult. ${ }^{14-16}$ We found that the intensity of the systolic murmur in the pulmonary area was increased during expiration. This variation is the opposite to that seen when the obstruction to outflow is 'fixed', where the murmur is of maximal intensity during inspiration, when there is an increased flow through the right heart. In hypertrophic cardiomyopathy the increase in right ventricular cavity size during inspiration reduces the amount of dynamic obstruction, and hence the intensity of the murmur is diminished during this phase of respiration.

While echocardiography is invaluable for detect- 
ing obstruction to left ventricular outflow, the technical difficulty of recording the systolic phase of pulmonary valve motion will tend to limit the value of the technique for detecting right ventricular obstruction in hypertrophic cardiomyopathy. The pulmonary valve was visualised in two of the three adults but this was only after careful searching and the diagnostic features might well remain unrecorded by a 'routine' study. Phonocardiography is, therefore, of particular importance in these patients. In the infant with Pompe's disease simulating hypertrophic cardiomyopathy the pulmonary valve was clearly recorded, showing a pattern typical of infundibular obstruction. In the only other report of a similar case, ${ }^{17}$ echocardiographic abnormalities of aortic and mitral valve motion were noted but no comment was made about pulmonary valve motion.

In summary, with subvalvar obstruction to right ventricular outflow there is turbulent blood flow past the pulmonary cusps and prolongation of right ventricular systole. The effects of these alterations of normal physiology may be detected by echocardiography and phonocardiography even in the presence of other cardiac abnormalities.

We thank Drs H Harned, S Schall, R Harrington, A Harris, and Mr J Parker for permission to report patients under their care.

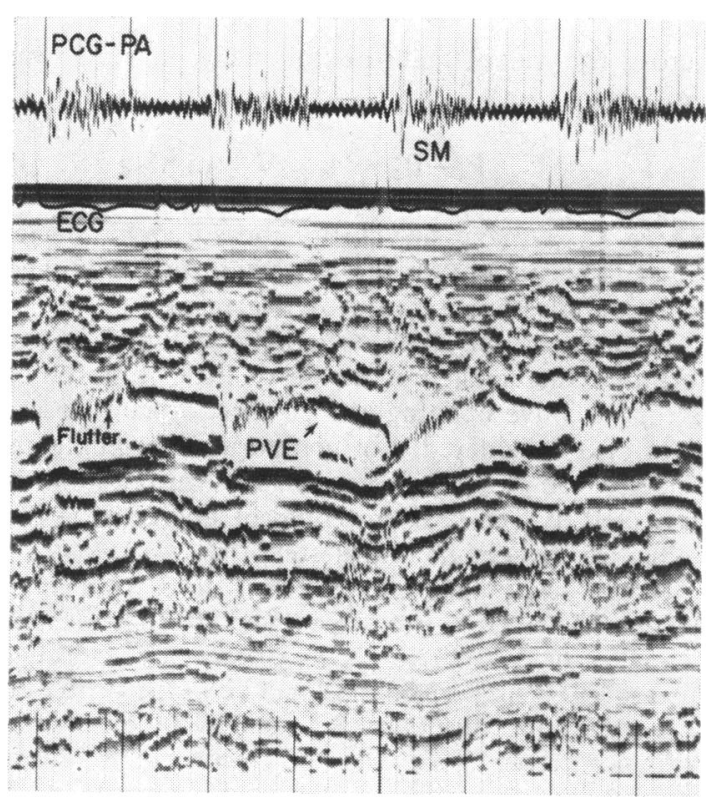

Fig. 8 Pulmonary valve echocardiogram in case 17. Fluttering and progressive closure of the pulmonary valve can be seen throughout systole. PVE, pulmonary valve echo.

\section{References}

${ }^{1}$ Hartmann AF Jr, Tsifutis AA, Arvidsson H, Goldring $D$. The two chambered right ventricle: report of nine cases. Circulation 1962; 26: 279-87.

${ }^{2}$ Weyman AE, Dillon JC, Feigenbaum $H$, Chang $S$. Echocardiographic differentiation of infundibular from valvular pulmonary stenosis. Am f Cardiol 1975; 36: 21-6.

${ }^{3}$ Davis RH, Feigenbaum H, Chang S, Konecke L, Dillon JC. Echocardiographic manifestations of discrete subaortic stenosis. Am $\mathcal{F}$ Cardiol 1974; 33: 277-80.

${ }^{4}$ Feizi O, Emanuel R. Echocardiographic spectrum of hypertrophic cardiomyopathy. Br Heart $\mathcal{f} 1975 ; 37$ : 1286-302.

${ }^{5}$ Nanda N, Gramiak R, Manning J, Lipchik E. Echocardiographic features of subpulmonic obstruction in dextrotransposition of the great vessels. Circulation 1975; 51: 515-21.

${ }^{6}$ Morris DC, Felner JM, Schlant RC, Franch RH. Echocardiographic diagnosis of tetraology of Fallot. Am f Cardiol 1975; 36: 908-13.

${ }^{2}$ Feigenbaum H. Echocardiography. Philadelphia: Lea \& Febiger, 1976.

${ }^{8}$ Jefferson K, Rees S. Clinical cardiac radiology. London: Butterworths, 1973: 157-8.

${ }^{9}$ Koretzky ED, Moller JH, Korns ME, Schwartz CJ, Edwards JE. Congenital pulmonary stenosis resulting from dysplasia of valve. Circulation 1969; 40: 43-53.

${ }^{10}$ Candraratna P, San Pedro S, Elkins R, Grantham N. Echocardiographic, angiocardiographic and surgical correlations in right ventricular myxoma simulating valvar pulmonic stenosis. Circulation 1977; 55: 619-22.

${ }^{11}$ Nanda N, Gramiak R, Robinson T, Shah P. Echocardiographic evaluation of pulmonary hypertension. Circulation 1974; 50: 575-81.

${ }^{12}$ Weyman AE, Dillon JC, Feigenbaum H. Echocardiographic patterns of pulmonic valve motion in pulmonary hypertension. Circulation 1974; 50: 905-10.

${ }^{13}$ Leatham A, Weitzman D. Asucultatory and phonocardiographic signs of pulmonary stenosis. Br Heart $\mathcal{F}$ 1957; 19: 303-18.

${ }^{14}$ Braunwald E, Lambrew C, Rockoff D, Ross J, Morris A. Idiopathic hypertrophic subaortic stenosis: 1. A description of the disease based upon an analysis of 64 patients. Circulation 1964; 29 and 30: Suppl. IV : 3-120.

${ }^{15}$ Falcone DM, Moore D, Lambert EC. Idiopathic hypertrophic cardiomyopathy involving the right ventricle. $A m$ f Cardiol 1967; 19: 735-40.

${ }^{16}$ Barr PA, Celermajer JM, Bowdler JD, Cartmill TB. Idiopathic hypertrophic obstructive cardiomyopathy causing severe right ventricular outflow tract obstruction in infancy. Br Heart $\mathcal{F} 1973$; 35: 1109-15.

${ }^{17}$ Rees A, Elbl F, Minhas K, Solinger R. Echocardiographic evidence of outflow tract obstruction in Pompe's disease (glycogen storage disease of the heart). Am F Cardiol 1976; 37: 1103-6.

Requests for reprints to Dr Peter Mills, Cardiac Department, The London Hospital, Whitechapel, London E1 1BB. 